\title{
Research on Active Power Filter Based on One-Cycle Control
}

\author{
Xin Shen \\ ${ }^{a}$ Yunnan Electric Power Test \& Research Institute, Kunming 650217, China
}

\begin{abstract}
One-cycle control (OCC) is a kind of nonlinear control technology. It is the most advanced reactive power compensation and harmonic suppression method. In the paper, a three-phase four-wire active power filter (APF) with one-cycle control is presented. This method does not need any measured quantities of three-phase input voltages and three-phase load currents, and also not need multipliers. The controller used has simple structure, which is composed of some integrators, flip-flops, comparators etc. The APF proposed has features of high precision and effective compensation. Through the theoretical analysis and the application by the OCC-APF, the results confirm that this approach can achieve the compensation in transient state and steady for the harmonic currents and reactive currents separately, and therefore, shows a good application prospect.
\end{abstract}

Keywords: One-cycle control, active power filter, reactive compensation, harmonic suppression

\section{Introduction}

With the development of the power grid, the problem of power quality becomes a topic of more and more concern. Many countries have formulated regulations and national standards of harmonic suppression. Keeping adequate margin of reactive power is the key guarantee for the safety, stability and economic operation of the power grid. Active power filter is a new type of power electronic devices used to suppress harmonics dynamically and compensate reactive current. At present, commonly-used control methods of active power filters are all depending on measured data of harmonic and reactive current, where the desired compensation current in the main circuit is generated by pulse width modulation (PWM) controllers. However, these methods not only need large amount of calculation but also have some defects caused by PWM control, such as hysteresis control switch frequency variation, triangle carrier wave distortion [1]-[2].

Large-signal nonlinear control technology was proposed for controlling the duty-ratio $d$ of a switch so that in each cycle the average value of a switched variable of switching converter is exactly proportional to the control reference in the steady state or in a transient. One-cycle control (OCC) technology is a novel large-signal nonlinear control scheme with significant advantages of fast dynamic response, excellent power source anti-interference, robust performance, and automatic switching error elimination. OCC takes advantages of the pulsed and nonlinear nature of switching converters to achieve instantaneous dynamic control of the average value of a switched variable. More specifically, the average value of the switched variable can reach a new steady-state after a transient in one switching cycle. There is no steady-state error or dynamic error between the control reference and the average value of the switched variable. OCC is developed to dynamically control the duty-ratio of a switch, so that in each cycle the average value of the switched variable is exactly equal to or proportional to the control reference. In one switching cycle, OCC restrains power source perturbations, and the controller eliminations switching errors, and thus the average value of the switched variable follows the dynamic reference.

OCC advantages are as following: 1) small size, low dissipation, good reliability of capacitance and no

Manuscript received July 20, 2012; revised August 20, 2012.

Corresponding author. Tel.: +86-13114253910; E-mail address: 23755803@qq.com.. 
complex circuits; 2) balanced AC waveform; 3) according to the different compensation requirement, the reactive power can be adjusted to lead or lag 90 degrees; 4) in a cycle, OCC can eliminate state error and dynamic error between switch variables and control reference signal; 5) it has a inverter that changes the unregulated power source voltage into a triangular voltage. If fault happened, it can adjust the parameter in time, and avoid current flow to fault point as far as possible; 6) the control circuit is simple. no need of multiplier, just need of controller, comparator, integrator and clock; 7) strong interference resistance ability; 8) non-contact switch opening and closing, and its high reliability much better than ordinary compensator switch [3]-[4]; 9) ease of integration.

\section{One-Cycle Control Technology}

In recent years, OCC technique has been successfully applied to the audio amplifier, high speed switch, power factor adjustment and DC-DC converters [5]-[8]. OCC technique was developed as a general pulse width modulator control method. It is also known as the integration-reset technique where the key element is the resettable integrator. This paper researches and analyzes a three-phase four-wire active power filter with three bridge arm based on OCC (OCC+APF-VAR), the theoretical analysis and experimental results show that the OCC+APF-VAR is not only a simple structure, but also strong dynamic and static performance compensation.

The OCC is composed of controller, comparator, multi-bit integrator and clock, as shown in Fig. 1. K1 and $\mathrm{K} 2$ are the complementary analog switches in pair. K1 is controlled by the function $k(t)$ :

$$
k(t)= \begin{cases}1 & 0<t<t_{\text {on }} \\ 0 & t_{\text {on }}<t<T_{s}\end{cases}
$$

where $T_{S}$ is the clock period, that is, the switching frequency $f_{S}=1 / T_{S}$.

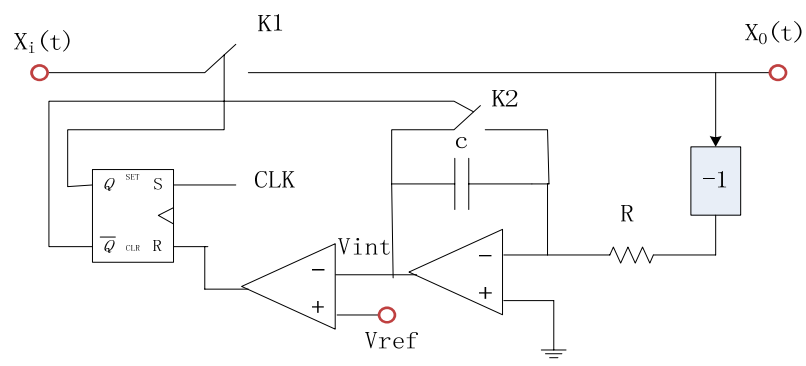

Fig. 1. Schematic of One-Cycle Control.

In each cycle, the switch is on for a time duration $t_{\text {on }}$ and off for a time duration $t_{\text {off }}$, where $T_{S}=t_{\text {on }}+t_{\text {off }}$. The duty ratio $d=t_{o n} \cdot\left(T_{S}\right)^{-1}$ is modulated by an analog control reference $v_{\text {ref }}$. When each switching cycle begins, the clock pulse signal is sent out, it makes $\mathrm{K} 1$ on state, $\mathrm{K} 2$ non-conducting state, the integrators begin to work for signal $x_{0}(t)$. While the integration of $v_{\text {int }}$ :

$$
v_{\text {int }}=\frac{1}{R C} \int_{o}^{t_{o n}} x(t) d t=v_{\text {ref }}
$$

equal to $v_{\text {ref, }}$, the comparator output flip by controller, it makes K1 non-conducting state, K2 on state, and the integrators reset immediately.

Since the switching frequency is constant, in the switching cycle, the $x(t)$ equal to the average of $x_{0}(t)$ :

$$
x(t)=\frac{1}{T_{s}} \int_{0}^{t_{\text {on }}} x_{0}(t) d t=K v_{\text {ref }}(t)
$$

where $K=R C \cdot\left(T_{S}\right)^{-1}$. The input signal $x_{0}(t)$ at the input node of the switch is chopped by the switch and transferred to the output node of the switch to form a switched variable $x_{1}(t)$. The frequency and the pulse width of the switching variable $x_{1}(t)$ is the same as that of the switching function $k(t)$, while the envelope 
of $x_{1}(t)$ is the same as the input signal $x_{0}(t)$, as shown in Fig. 5. Then the average value of the switched variable at the switch output is exactly equal to control reference in each cycle, since the switching period is constant. Therefore, the average of the switched variable is instantaneously controlled within one cycle.

For the switch period, $T_{S}$ is constant and also $K=1 / k T_{S}$ is a constant, the average value of the switched variable at the switch output $x(t)$ is guaranteed to be in each cycle.

The control reference is a function of time, and the average of the diode-voltage is equal to the time variant control reference in each cycle. By adopting the method, it can realize linear control through the average of the switch variables equal or in certain proportion to the control switch reference signal in each switch cycle.

\section{Three-Phase Four-Wire Active Power Filter with Three Bridge Arm Based on OCC}

\subsection{Analysis of main circuit}

Fig. 2 is the schematic capture of three-phase four-wire active power filter with three bridge arm based on OCC. The OCC controller is connected to the middle of the two capacitors in the DC converter, the controller controls the 6 switches opening and closing.

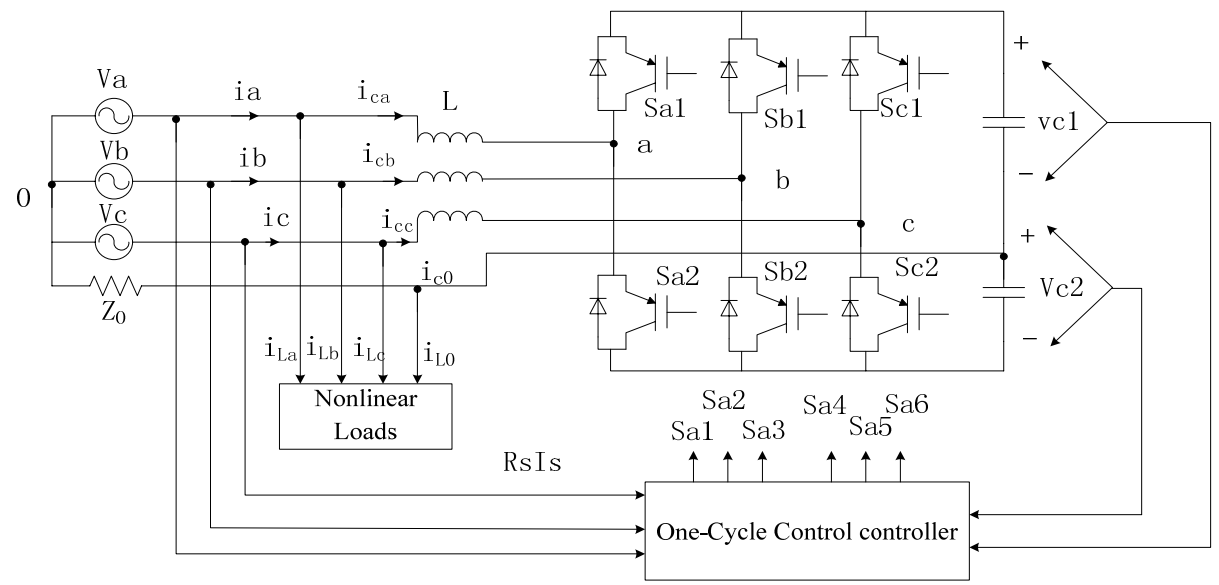

Fig. 2. Schematic Capture of three-phase four-wire active power filter with three bridge arm based on OCC.

The duty cycle of the switches Sa1, Sb1 and Sc1 respectively in a cycle in DC converter, so that the duty cycle of the switches, the value of Sa2, Sb2 and Sc2 are $\left(1-d_{a}\right),\left(1-d_{b}\right)$ and $\left(1-d_{c}\right)$. Thus, we can obtain the following relationship:

$$
\left\{\begin{array}{l}
v_{a 0}=d_{a} v_{c 1}+\left(1-d_{a}\right)\left(-v_{c 2}\right) \\
v_{b 0}=d_{b} v_{c 1}+\left(1-d_{b}\right)\left(-v_{c 2}\right) \\
v_{c 0}=d_{c} v_{c 1}+\left(1-d_{c}\right)\left(-v_{c 2}\right)
\end{array}\right.
$$

The relative neutral point voltage of the panel points a, b and c as following:

$$
\left\{\begin{array}{l}
v_{a 0}=v_{a}+v_{L} \\
v_{b 0}=v_{b}+v_{L} \\
v_{c 0}=v_{c}+v_{L}
\end{array}\right.
$$

In Eq. (4), the inductance value of high frequency circuits is very little, and the voltage of inductance is far less than the phase voltage, therefore, the voltage of inductance $V_{L}$ is ignored. Eq. (5) becomes

$$
\left\{\begin{array}{l}
v_{a 0}=v_{a} \\
v_{b 0}=v_{b} \\
v_{c 0}=v_{c}
\end{array}\right.
$$

Two capacitor voltages in the DC converter should be equal in normal operation condition, so that 
$V_{c 1}=V_{c 2}=V_{c}$. From Eq. (4) and Eq. (6), the switch duty cycle relationship of the power voltage and the capacitor voltages in DC converter can be given by

$$
\left\{\begin{array}{l}
v_{a}=\left(2 d_{a}-1\right) v_{c} \\
v_{b}=\left(2 d_{b}-1\right) v_{c} \\
v_{c}=\left(2 d_{c}-1\right) v_{c}
\end{array}\right.
$$

\subsection{OCC equations}

The compensation target of OCC+APF is committed to load symmetry and unit power factor close to 1 . According to the basic circuit principle, we have

$$
\left\{\begin{array}{l}
v_{a}=R_{e} \cdot i_{a} \\
v_{b}=R_{e} \cdot i_{b} \\
v_{c}=R_{e} \cdot i_{c}
\end{array}\right.
$$

where $R_{e}$ is the input source equivalent resistance when three-phase harmonic and reactive current are compensated. From Eq. (7) and Eq. (8), we have

$$
\left\{\begin{array}{l}
R_{e} i_{a}=\left(2 d_{a}-1\right) v_{c} \\
R_{e} i_{b}=\left(2 d_{b}-1\right) v_{c} \\
R_{e} i_{c}=\left(2 d_{c}-1\right) v_{c}
\end{array}\right.
$$

where $v_{m}=\left(R_{s} / R_{e}\right) v_{c}$ ( $R_{s}$ is the current measurement resistance). Thus, the three-phase four-wire active power filter with three bridge arm based on OCC can be expressed as

$$
\left\{\begin{array}{l}
R_{s} i_{a}=\left(2 d_{a}-1\right) v_{m} \\
R_{s} i_{b}=\left(2 d_{b}-1\right) v_{m} \\
R_{s} i_{c}=\left(2 d_{c}-1\right) v_{m}
\end{array}\right.
$$

In actual operation, the DC converter $V_{c 1}$ is not fully equal to $V_{c 2}$. According to Eq. (4), we achieve

$$
\left\{\begin{array}{l}
v_{a 0}=d_{a}\left(v_{c 1}+v_{c 2}\right)-v_{c 2} \\
v_{b 0}=d_{b}\left(v_{c 1}+v_{c 2}\right)-v_{c 2} \\
v_{c 0}=d_{c}\left(v_{c 1}+v_{c 2}\right)-v_{c 2}
\end{array}\right.
$$

Let $v_{c 2}=v_{c}, \quad \Delta v=v_{c 1}-v_{c 2}$, Eq. (11) becomes

$$
\left\{\begin{array}{l}
v_{a 0}=d_{a} \Delta v+\left(2 d_{a}-1\right) v_{c} \\
v_{b 0}=d_{b} \Delta v+\left(2 d_{b}-1\right) v_{c} \\
v_{c 0}=d_{c} \Delta v+\left(2 d_{c}-1\right) v_{c}
\end{array}\right.
$$

Applying Eq. (6), Eq. (8), Eq. (9), Eq. (10) and Eq. (12) yields

$$
\left\{\begin{array}{l}
R_{s} i_{a}=\frac{R_{s} d_{a}}{R_{e}} \Delta v+\left(2 d_{a}-1\right) v_{m} \\
R_{s} i_{b}=\frac{R_{s} d_{b}}{R_{e}} \Delta v+\left(2 d_{b}-1\right) v_{m} \\
R_{s} i_{c}=\frac{R_{s} d_{c}}{R_{e}} \Delta v+\left(2 d_{c}-1\right) v_{m}
\end{array}\right.
$$

Eq. (13) shows the relationship of switch duty cycle, input source current, DC side voltage, and DC side capacitor voltage. Fig. 3 is the controller model schemes designed according to Eq. (13). 


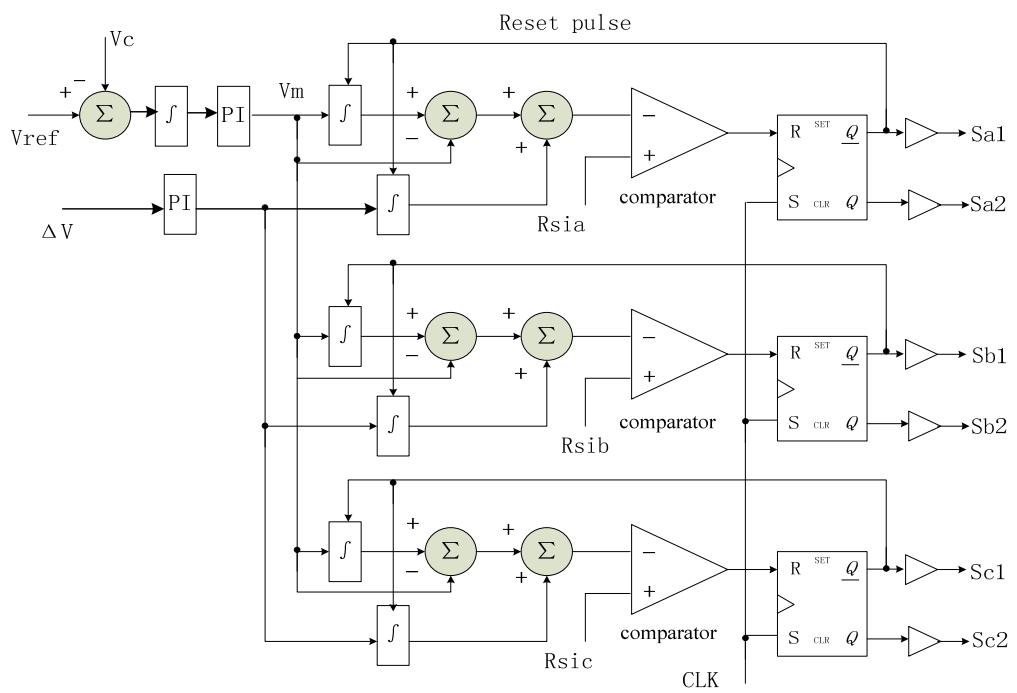

Fig. 3. Controller model schemes.

In the case that DC capacitor voltage fluctuation affects the filter's effective work [10], the imbalance of the DC capacitor voltage can be effectively inhibited by applying hysteresis current control and proportional integral (PI) regulator.

From Fig. 3, the control circuit is composed of multi-bit integrator, comparator, clock and linear elements. The control process is that: when the pulse coming, integrator begins to integrate the error of DC capacitor voltage and its reference. When the integrator meets the requirements of Eq. (10), the signal flips and the integrator resets and keeps voltage output. Then the next clock pulse comes and the switch cycle repeats. In each cycle, OCC technology makes the average value of the switched variable exactly equal to or proportional to the control reference through controlling the switch duty cycle. The function of OCC is to prevent the error in the present cycle entering the next cycle.

\section{Analysis of Experiment Result}

Experiments were conducted to study the feasibility of OCC. The OCC+APF-VAR device was installed between in the power grid and load. By compensating the load current, the cleanness of power grid can be maintained and the corresponding power factor is provided to the load. Before compensation, the three-phase current waveform, with serious distortion, appears like square wave, as shown in Fig. 4. After OCC+APF-VAR compensation, the three-phase current is improved a lot, its waveform appears in sine wave form, as shown in Fig. 5.
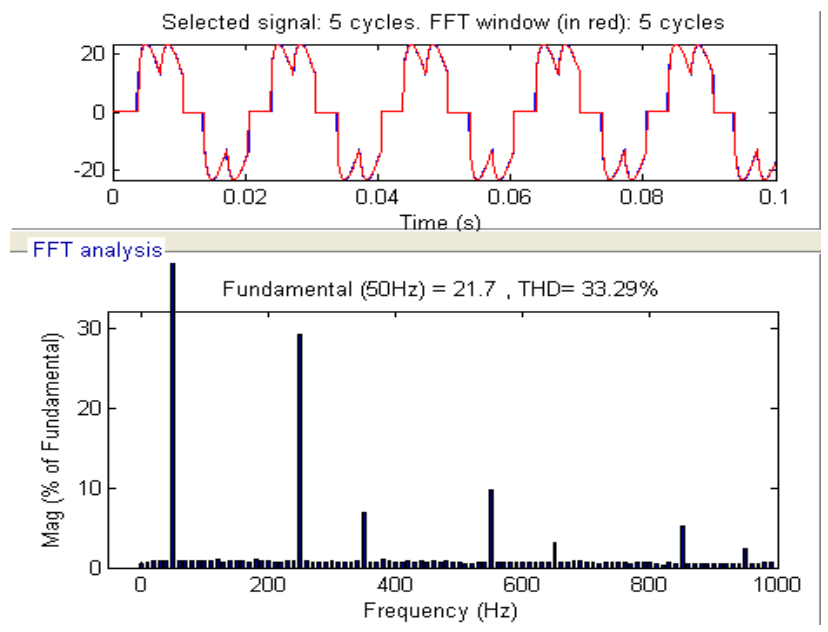

Fig. 4. Current compensation actual measuring waveform in power grid 


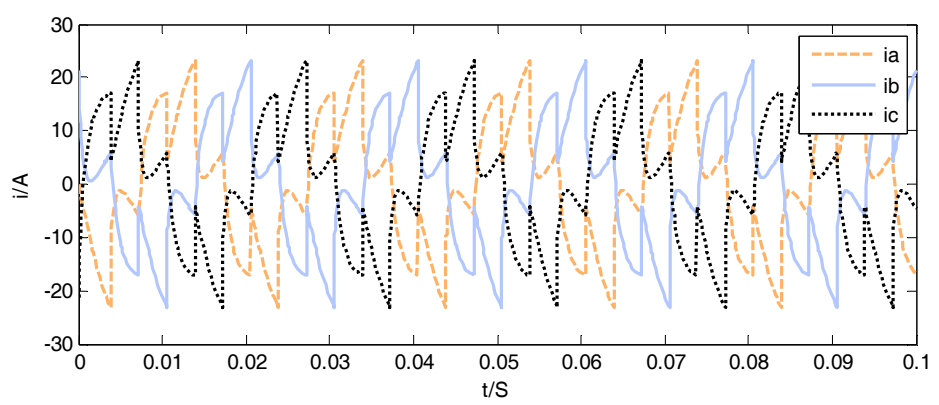

(a)

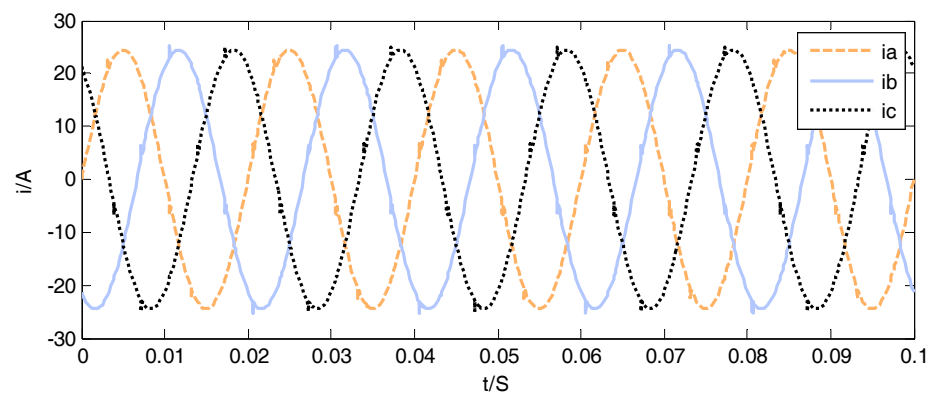

(b)
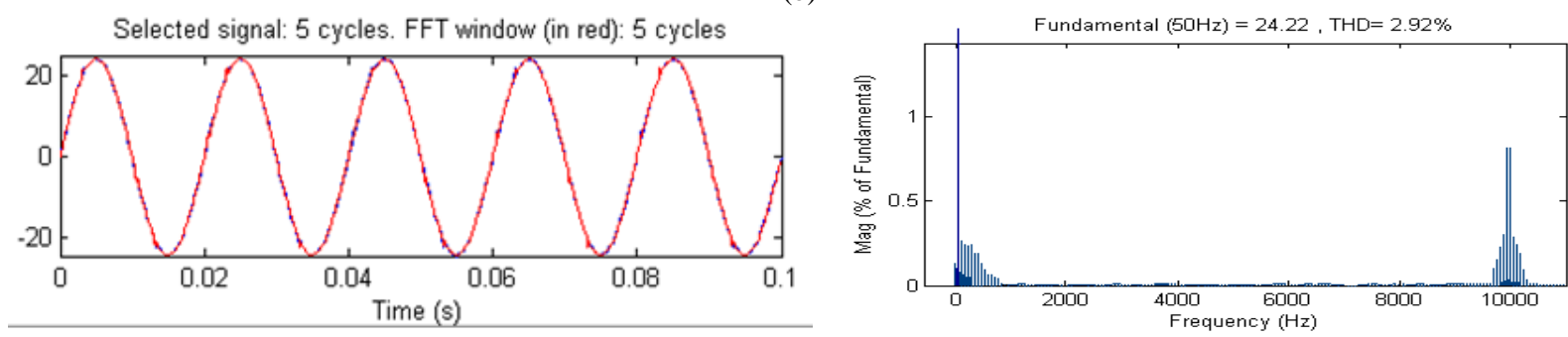

(c)

Fig. 5. Response waveforms: (a) dynamic response compensatory current waveform, (b) compensated dynamic response test waveform, and (c) spectrum with current compensation.

As a large-signal nonlinear control technique, OCC is developed to dynamically control the duty-ratio $d$ of a switch. Theoretically, APF-VAR with OCC is capable of rejecting the power source perturbations completely and the average value of the switched variable at a switch node can follow its control reference within one cycle. Therefore, there is no steady state error or dynamic error between the control reference and the average value of the switched variable.

When the OCC technique is used to control a discrete switch, the input signal and the control reference of a switch are independent variables since the duty-ratio of the switch in OCC method purely depends on the states of the current switching cycle. When a switch is embedded in a complex system, the input signal of the switch may be a function of the output signal of the switch.

\section{Conclusions}

This paper describes a three-phase four-wire active power filter with three bridge arm based on OCC. OCC+APF-VAR is used to suppress harmonic dynamically and compensate reactive power. OCC+APFVAR restrains the perturbations in power source in one switching cycle, the controller eliminates switching errors in one switching cycle, and therefore, the average value of the switched variable can follow the control reference in one switching cycle.

The results presented in this paper show that OCC+APF-VAR technique can provide fast dynamic response, excellent power source perturbation rejection, robust performance, and automatic switching error correction, and it will have great economic and broad application prospect in power systems. 


\section{References}

[1] Liu Y, Xu SZ. Simulation research of SAPF based on improved hysteresis control strategy. Industrial and Mian Automation, 2010; 36(6):74-76.

[2] Wang XQ, Zhang DR. Carrier-reversed current tracking PWM control. Science and Technology of West China, 2009; 8(12):4-7.

[3] Smedley KM, Zhou L, Qiao C. Unified constant-frequency integration control of active power filters-steady-state and dynamics. IEEE Trans. on Power Electronics, 2001; 16(3):428-436.

[4] Smedley KM, Zhou L, Qiao C. Unified constant-frequency integration control of active power filters-steady-state and dynamics. IEEE Trans. Power Electronics, 2001; 16(3):428-436.

[5] Lai Z, Smedley KM. A new extension of one-cycle control and its application to switching power amplifiers. IEEE Trans. Power Electronics, 1996; 11(1):99-105.

[6] Smedley KM, Cuk S. Dynamics of one-cycle controller Cuk converters. IEEE Trans Power Electronics, 1995; 10(6):634-639.

[7] Lai Z, Smedley KM. A family of continuous-conduction-mode power-factor-correction controllers based on the general pulsewidth modulator. IEEE Trans. Power Electronics, 1998; 13(3):501-510.

[8] Smedley KM, Zhou L, Qiao C. Unified constant-frequency integration control of active power filters-steady-state and dynamics. IEEE Trans. Power electronics, 2001; 16(3):428-436.

[9] Zhuang H, Zhou L, Zhang DH. Study on one-cycle controlled three-phase four-wire active power filter with four-leg. Relay, 2007; 35(24):36-39.

[10] Aredes M, Hafner J. Three-phase four-wire shunt active filter control strategies. IEEE Trans Power Electronics, 1997; 12(2):311-318.

[11] Jin TT, Chen XF, Smedley KYM. A new one-cycle controlled FACTS element with the function of STATCOM and active power filter. IEEE Trans. on Industrial Electronics, 2003; 3:2634-2638.

[12] Yu FB, Liang GN, Zhong LX. A novel three-phase four-wire active power filter with one-cycle control. Electro Technical Application, 2006, 25(1):90-94.

[13] Wang Y, Shen SH. Research on one-cycle control for switching converters. In: Proc. of the Word Congress on Intelligent Control and Automation, 2004:74-77.

[14] Smedley KM, Cuk S. Dynamics of one-cycle controlled cuk converters. IEEE Trans. Power Electronics, 1995; 10(6):634-639.

[15] Smedley KM, Zhou LW. Unifed constant-frequency integration control of active power filters-steady-state and dynamics. IEEE Trans. Power Electronics, 2001; 16(3):428-436.

[16] Qiao CM, Smedley KM. Acomprehensive analysis and design of a single phase active power filter with unified constantfrequency integration control. In: Proc. of IEEE Power Electronics Specialists Conference, 2001:1619-1625.

[17] Qiao CM, Smedley KM. Three-phase active power filter with unified constant-frequency control. Presented at: the 3rd International Power Electronic and Motion Control Conference, 2000.

[18] Chen GZ, Smedley KM. Steady-state and dynamic study of one-cycle controlled three-phase power-factor correction. IEEE Trans. on Industrial Electronics, 2005; 52(2):355-362.

[19] Akagi H, Nabae A, Atoh S. Control strategy of active power filters using multiple voltage-source PWM converters. IEEE Trans. on Industry Applications, 1986; 22(3):460-465. 